\title{
The minute monogonont rotifer Proales similis de Beauchamp: culture and feeding to small mouth marine fish larvae
}

Stenly Wullur ${ }^{\mathrm{a}, \mathrm{b}}$, Yoshitaka Sakakura ${ }^{\mathrm{c}}$, Atsushi Hagiwara ${ }^{\mathrm{a}, *}$

a Graduate School of Science and Technology, Nagasaki University, Nagasaki 852-8521, Japan

b Faculty of Fisheries and Marine Science, Sam Ratulangi University, Manado 95115, Indonesia

c Faculty of Fisheries, Nagasaki University, Nagasaki 852-8521, Japan

*Corresponding author

Atsushi Hagiwara

Tel/fax: +8195819 2830

E-mail address: hagiwara@nagasaki-u.ac.jp 


\section{Abstract}

The body length and width of Proales similis (mean \pm SD; $83 \pm 11 \mu \mathrm{m}$ and $40 \pm 6 \mu \mathrm{m}$, respectively) is 38.1\% smaller and 60.3\% narrower than that of Brachionus rotundiformis. Due to its small size, $P$. similis has potential for rearing marine fish larvae which require first food smaller than $B$. rotundiformis. We examined the feasibility of using $P$. similis as live food by analyzing its life history, population growth and feeding incidence by fish larvae. P. similis produced first offspring on 2.5-2.8 days after hatch. Females produced 4.3-7.8 offspring during their 2.9-3.4 day reproductive period. $P$. similis grew well at temperatures 25 to $35^{0} \mathrm{C}$ (density $=250$ to 1030 ind. $/ \mathrm{ml} ; r=0.68$ to 0.81 day $^{-1}$ ) and at salinities 2 to 15 ppt (density $=360$ to 500 ind. $/ \mathrm{ml} ; r=0.73$ to 0.78 day $^{-1}$ ). Population density of $P$. similis was higher than $B$. rotundiformis after 8 days of culture period with either $N$. oculata and $C$. vulgaris as food. In mass culture, population density of $P$. similis increased from 25 to 2,400 ind./ml ( $r=0.42$ day $^{-1}$ ) after 11 days. Results from feeding experiments confirm that $P$. similis is consumed by seven-band grouper (Epinephelus septemfasciatus) larvae. The larvae demonstrated the highest feeding rate at $20 \mathrm{ind} . / \mathrm{ml}$ of $P$. similis.

Keywords: Rotifera, Proales similis, Brachionus rotundiformis, culture, live food, larviculture, Epinephelus septemfasciatus. 


\section{Introduction}

Marine fish hatcheries culture rotifers of the Brachionus plicatilis species complex as the initial live food for several marine fish larvae. The B. plicatilis species complex were traditionally classified morphologically as SS (super-small), S (small) and L (large) type, with lorica length around 90-150, 100-210 and 130-340 $\mu \mathrm{m}$, respectively (Hagiwara et al., 2001). We now recognize these morphotypes as different species, with the SS type being classified as B. rotundiformis (Segers, 1995). Due to its small lorica size, $B$. rotundiformis (Fig. 1) is mostly used as a starter food for feeding fish larvae with small mouths, but it is not satisfactory as starter food for those fish with even smaller mouths, like groupers in the genus Epinephelus (Okumura, 1997), Napoleon fish (Cheilinus undulatus) or Angelfishes (family Pomachantidae). Larvae of the two latter fish, require specifically small live food of about $40-80 \mu \mathrm{m}$ at initial feeding stages (Slamet and Hutapea., 2004; Olivotto, et al., 2006). Recognizing this demand for smaller sized live food, we have developed $P$. similis as a starter live food organism for rearing small mouth fish larvae. For that purpose, we explored the culture of $P$. similis under various environmental conditions to determine optimal conditions for the culture of this species. Population growth and mean body size was compared to $B$. rotundiformis cultured in similar conditions. We also investigated the potential of $P$. similis as live food for fish larviculture by observing whether seven-band grouper larvae can ingest this rotifer. 


\section{Materials and methods}

P. similis (Fig. 1) was collected using a $45 \mu \mathrm{m}$ mesh plankton net from an estuary $\left(24^{0} \mathrm{~N}: 124^{0} \mathrm{E}\right)$ on Ishigaki Island, Okinawa, Japan on July 2004. The water temperature and salinity at the time of collection were $27^{\circ} \mathrm{C}$ and $2 \mathrm{ppt}$, respectively. $P$. similis was acclimatized to higher salinity and a clonal culture of $P$. similis was established in the laboratory in 2 and 22 ppt diluted seawater at $25^{\circ} \mathrm{C}$. Nannochloropsis oculata grown in KW-21 medium (Daiichi Seimou Co.Ltd, Japan) was provided as food. The $B$. rotundiformis (Indonesian strain) (Hagiwara et al., 1995; Rumengan et al., 1998) was used for comparison to $P$. similis. Both species are common in tropical and subtropical region.

\subsection{Life history parameters}

We investigated life history parameters of $P$. similis at salinities of 2, 15, and 25 ppt, at $25^{0} \mathrm{C}$ in darkness. $\quad N$. oculata was provided at a density of $2.5 \times 10^{6}$ cells $/ \mathrm{ml}$. Prior to the experiment, $P$. similis was cultured in the salinity treatments for at least one week to permit acclimation. From these cultures, a number of adults identified by their body size were selected and were allowed to produce amictic eggs. Fifty neonates ( $<4$ h old) were selected and cultured individually in $1 \mathrm{ml}$ fresh medium and used as test animals. Observations were conducted every $12 \mathrm{~h}$ to distinguish between an adult rotifer and newly formed neonates and the data pooled daily. The number of offspring produced by each female was counted and only the maternal female was transferred to fresh medium until the 
all test animals died. Lifespan, reproductive period, generation time, fecundity and intrinsic rate of population increase $(r)$ were determined. Intrinsic rate of natural increase $r$ was calculated by using the following equation (Lotka, 1913);

$$
\sum_{\mathrm{x}=0}^{\mathrm{n}} l_{x} m_{x} \exp (-r x)=1
$$

Other demographic parameters were obtained by the following:

Net reproduction rate: $\quad R o=\sum_{\mathrm{x}=0}^{\mathrm{n}} l_{x} m_{x}$

Generation time: $\quad T=1 /$ Ro $\sum_{\mathrm{x}=0}^{\mathrm{n}} l_{x} m_{x} x$

where, $x=$ age $(0,1, \ldots \mathrm{n}$ days $), l_{x}=$ age-specific survival from birth to age $x, m_{x}=$ age-specific fecundity, $R_{0}=$ net reproductive rate and $T$ =generation time. A one-way ANOVA and Tukey-Kramer's test was performed to compare live history parameters among the salinity levels.

\subsection{Population growth and body size}

Three different experiments were performed to examine the effect of temperature, salinity and food density on population growth of $P$. similis. A first experiment to test the temperature effect was performed by combining 15, 20, 25, 30 and $35^{\circ} \mathrm{C}$ with 2 and 25 ppt salinity. A second experiment to test the effect of salinity was performed using 2, 15, 20, 25 and 30 ppt at $25^{\circ} \mathrm{C}$. A third experiment focused on the food density effect was 
performed at $25^{\circ} \mathrm{C}$, by combining 2 and 25 ppt salinity with two types of food (the microalgae N. oculata and Chlorella vulgaris; Super Chlorella V-12®, Chlorella Industry Co.) and four food levels (1.2, 5.8, 17.3 and $28.8 \mu$ g dry weight/ml), altogether summing up to 16 experimental conditions. The two microalgae used were obtained as concentrated liquid solution and a dry weight of $28.8 \mu \mathrm{g} / \mathrm{ml}$ corresponds to $12.5 \times 10^{6}$ and $4.3 \times 10^{6}$ cells $/ \mathrm{ml}$ for N. oculata and C. vulgaris, respectively. Experiments were conducted using 24-well polystyrene plates (Iwaki, Japan) containing $3 \mathrm{ml}$ culture medium in darkness. For each treatment, there were three to six replicates.

To begin each experiment, three adult rotifer were transferred into their treatment and the initial day was called day 0. Observations were made once every two days, when the number of living individuals was counted and transferred to new wells containing fresh culture medium and food suspension. Population growth of $P$. similis was compared to $B$. rotundiformis cultured in similar conditions. The population growth rates $(r)$ were calculated using the following equation (Krebs, 1985);

$$
r=(\ln N t-\ln N o) / t
$$

Where, $\mathrm{ln}=$ natural logarithm, $\mathrm{Nt}=$ population after time $\mathrm{t}$ (days) and $\mathrm{No}=$ initial population. Population density of the rotifers on day 8 in the experiments of temperature and food density were compared using a two-way ANOVA, while the experiment on salinity was compared using one-way ANOVA. A Tukey-Kramer test was calculated to determine significantly different treatments in each experiment. Student $t$-test was used for 
comparing the population density of the rotifers in each food density.

A total of 480 individuals of $P$. similis and B. rotundiformis obtained on day 8 from each food treatment in the experiment of food density $\left(25 \mathrm{ppt} ; 25^{0} \mathrm{C}\right)$ were measured for their total length, body length and width (Fig.1) at 450x of magnification, with a digital microscope (Keyence VH-8000, Keyence Corp.). Prior to measurement, the rotifers were anesthetized with $0.002 \%$ MS-222 (Tricaine; Sigma Chemical Co., USA) to prevent shrinkage. A Student $t$-test was used to compare body size of the two species of rotifers.

\subsection{Mass culture and salinity change}

Mass culture of $P$. similis was conducted in three 2-l polyethylene containers containing $2 \mathrm{l}$ diluted seawater ( $25 \mathrm{ppt}$ salinity) maintained at $25^{\circ} \mathrm{C} . \quad N$. oculata was used as food at $1.25 \times 10^{7}$ cells $/ \mathrm{ml}$ (equal to $28.8 \mu$ g dry weight $/ \mathrm{ml}$ ). The density was controlled daily by counting the number of microalgae in a haemacytometer and adjusting the density. Constant aeration at $100 \mathrm{ml} / \mathrm{min}$ controlled by a flow meter (Kofloc RK-1350V) was provided to each culture. The experiment was initiated by stocking $P$. similis at 25 individuals/ml and the culture was observed until exponential growth stopped. Daily sampling consisted of taking a $1 \mathrm{ml}$ sample from each container and the number of rotifers was counted to determine density. Population growth rate was calculated using the same equation as described previously.

To test $P$. similis survival after changing salinity from 25 to $35 \mathrm{ppt}$, the following 
experiment was conducted. A total of 21 wells of a 24-well polystyrene plate were filled with $1 \mathrm{ml}$ seawater (35 ppt) containing C. vulgaris at density $0.5 \times 10^{6}$ cells/ml at $25^{0} \mathrm{C}$. Ten individual of $P$. similis cultured at salinity 25 ppt were individually transferred to the 35 ppt medium by a micropipette. Observation was made by counting the total number of live rotifers in each culture medium at 0, 4, 8, 12, 24, 48 and 72 hours (in three replicates) after the transfer.

\subsection{Feeding experiment on fish larvae}

To investigate whether fish larvae can consume $P$. similis, seven-band grouper $E$. septemfasciatus larvae were tested due to their small mouth size $(180 \pm 20 \mu \mathrm{m})$. The experiment was conducted in fifteen 30-l polycarbonate tanks in a controlled-room temperature at $25^{\circ} \mathrm{C}$. Photoperiod during the experiment was $12 \mathrm{~L}: 12 \mathrm{D}$. The rearing tanks were filled with artificial seawater with salinity at $34 \pm 1$ ppt (Marine artHi, Tomita Pharmaceutical Co. Ltd., Tokushima, Japan). The bottom of the rearing tank was filled with ceramic sand (MS-10, Micros Ceramic, Norra Co. Ltd, Kyoto, Japan) to maintain water quality. Gentle aeration was provided by an air stone placed on the bottom center of the rearing tanks. Fertilized eggs of seven-band grouper larvae obtained from Nagasaki Prefectural Fisheries Experimental Station were stocked in the rearing tanks at a density of 10 eggs/l. The eggs hatched on the following day. An oil film (Yamaoka et al., 2000) was introduced on the surface of each rearing tank at a concentration of $0.2 \mathrm{ml} / \mathrm{m}^{2}$, to prevent 
surface entrapment of the larvae. First feeding occurred on day 4 after hatching (DAH), at which time five dietary treatments of $P$. similis (10, 20 and $30 \mathrm{ind} . / \mathrm{ml}), B$. rotundiformis (10 ind./ml) and a mixture of the rotifer species (consisting of $5 \mathrm{ind} . / \mathrm{ml}$ of each P. similis and $B$. rotundiformis) were offered to the larvae in three replicates. Prior adding to the larval rearing tanks, the rotifers were cultured $\left(25 \mathrm{ppt} ; 25^{0} \mathrm{C}\right)$ with concentrated liquid $C$. vulgaris (Super fresh Chlorella V-12®, Chlorella Industry Company), for nutritional enrichment. The concentrated liquid C. vulgaris was also introduced to the larval rearing tanks at density of $0.5 \times 10^{6}$ cells $/ \mathrm{ml}$. The fish larvae were fed for 24 hours and all live larvae were counted 48 hours later to determine the survival. Percent survival was calculated from the numbers of eggs stocked. In order to examine feeding of the larvae, about 10 larvae from each tank were anesthetized with $0.01 \%$ MS-222 and fixed with 5\% formalin solution. Number of larvae that fed on rotifers was investigated by examining the presence of trophi or undigested rotifers inside the gut of larvae. A one-way ANOVA and Tukey-Kramer's test was used to compare feeding incidence of the fish larvae.

\section{Results}

\subsection{Life history parameters}

Lifespan, reproductive period and generation time of $P$. similis ranged from 4.0 4.7, 2.4 - 2.8 and 2.4 - 2.8 days, respectively. The fecundity was significantly higher at 2 ppt than at higher salinities (Tukey-Kramer test, $p<0.05$ ). The intrinsic rate of population 
increase $(r)$ ranged from 0.63 to 0.93 day $^{-1}$ at salinities of 2 to 25 ppt, respectively (Table 1 )

\subsection{Population growth and body size}

Maximum population densities of $P$. similis during 8 day culture period were compared among temperature, salinity (Fig. 2) and food density treatments (Fig. 3). Rotifer density reached to maximum on day 8 except at 15 and $20^{\circ} \mathrm{C}$. A two-way ANOVA showed that the effect of temperature was significant on population density of $P$. similis cultured at salinity 2 and 25 ppt $(p<0.05)$. Tukey-Kramer tests for the two salinity groups (2 and $25 \mathrm{ppt}$ ) showed that rotifer density at temperatures 25 and $35^{\circ} \mathrm{C}$ (250 to 1030 ind./ml with $r=0.68-0.81$ day $^{-1}$ ) was significantly higher than that at $<20^{0} \mathrm{C}$ (density $<2$ ind./ml) (Fig. 2-I). The effect of salinity was also significant on population density of $P$. similis (ANOVA, $p<0.05$ ). Significantly higher rotifer density was observed at salinity 2 and 15 ppt (500 and 360 ind./ml with $r=0.78$ and 0.73 day $^{-1}$, respectively) than those at higher salinities (< 120 ind./ml) (Tukey-Kramer, $p<0.05$ ) (Fig. 2-II). The effect of the experimental environment $25^{\circ} \mathrm{C}$ and 25 ppt was tested twice, one in each of the experiments reported above. Maximum population densities (mean $\pm S D, n=3-6$ ) were quite different (250 \pm 116 ind./ml with $r=0.68$ day $^{-1}, 25^{0} \mathrm{C}$ in Fig. 2-I to $110 \pm 118$ ind./ml with $r=0.55$ day $^{-1}$ for salinity 25 ppt, in Fig. 2-II). However, they were not significantly different (t-test, $p<0.05)$. Two-way ANOVA showed that the density of $N$. oculata significantly affected population density of $P$. similis cultured at 2 and 25 ppt $(p<0.05)$. Tukey-Kramer 
test on the two salinity groups (2 and $25 \mathrm{ppt}$ ) revealed that the population densities of $P$. similis at $N$. oculata densities of 17.3 and $28.8 \mu \mathrm{g}$ dry weight $/ \mathrm{ml}(2,270$ to $2,450 \mathrm{ind} . / \mathrm{ml})$ were significantly higher than those at 1.2 and $5.8 \mu$ g dry weight $/ \mathrm{ml}$ (250 to $520 \mathrm{ind} . / \mathrm{ml}$ ) at 2 ppt, but not significant at salinity 25 ppt. $\quad$ P. similis cultured at salinity 25 ppt showed significantly high population density than $B$. rotundiformis at most $N$. oculata densities (t-test, $p<0.05)$. The $B$. rotundiformis showed a significantly different population density with increasing $N$. oculata density (Tukey-Kramer, $p<0.05$ ) (Fig. 3-I). Similar effects on population density of the two rotifers as in the $N$. oculata were also observed on the densities of C. vulgaris (Fig. 3-II).

Total length, body length and width of $P$. similis did not vary among food treatments. The total length distributed between 50-150 $\mu \mathrm{m}$ (mean \pm SD; $109 \pm 15 \mu \mathrm{m}$ ) while the body length distributed between $40-110 \mu \mathrm{m}(83 \pm 11 \mu \mathrm{m})$. The body length was significantly smaller (38.1\% smaller) than lorica length of B. rotundiformis which ranged from $70-170 \mu \mathrm{m}(134 \pm 14 \mu \mathrm{m})(t$-test, $p<0.05)$. Body width of $P$. similis ranged from $10-50 \mu \mathrm{m}(40 \pm 6 \mu \mathrm{m})$ and was significantly narrower $(60.3 \%)$ than lorica width of $B$. rotundiformis, which ranged from 50-150 $\mu \mathrm{m}(102 \pm 12 \mu \mathrm{m})(t$-test, $p<0.05)$ (Fig. 4).

\subsection{Mass culture and salinity change}

Exponential growth of $P$. similis mass-cultured in 2-l containers by feeding $N$. oculata at $28.8 \mu \mathrm{g}$ dry weight/ml is shown in Fig. 5. P. similis grew from $25 \mathrm{ind} . / \mathrm{ml}$ on 
day 0 to 2,400 ind./ml on day 11 , with a mean $r$-value of 0.42 day $^{-1}$.

Transferring $P$. similis from salinity 25 to 35 ppt for $0,4,8,12,24,48$ and 72 hours did not significantly influence the total number of rotifers. Since rotifers grew during observation, percentages of the initial number of rotifers after salinity change were $100 \%$, $103.3 \% \pm 5.8,107.7 \% \pm 5.8,103.3 \% \pm 5.8,113.3 \% \pm 11.5,100 \% \pm 10.0$ and $103 \% \pm 20.8$, respectively.

\subsection{Feeding experiment on fish larvae}

Percent survival of seven-band grouper larvae after 24 hours of feeding experiment were $2.4,6.7,4.5,1.0$ and 3.2 in dietary treatments of $P$. similis at 10, $2030 \mathrm{ind} . / \mathrm{ml}, B$. rotundiformis at $10 \mathrm{ind} . / \mathrm{ml}$ and mixed rotifer species at $10 \mathrm{ind} . / \mathrm{ml}$, respectively, and was not significantly different among treatments. Based on gut content analysis, higher feeding incidence and lower variation among rearing tanks at the onset of first feeding (4 DAH) of seven-band grouper larvae was observed in the treatments fed P. similis 20 ind./ml than those at 10 and 30 ind./ml (Fig. 6). In this treatment, the percentage of feeding larvae reached $95 \%$ while it was only $55 \%$ and $75 \%$ in the treatments fed $B$. rotundiformis alone or a mixture of the two rotifer species, respectively.

\section{Discussion}

Determining optimal culture conditions and limits for population growth of live 
food for fish larviculture is required prior to its mass production. Another important factor is to determine whether fish larvae ingest the organism. For mass culture, salinity, temperature and food levels are considered as important. Results in the present study show that salinity ranging between 2 and 30 ppt has no significant effect on lifespan and reproductive period of $P$. similis, but low salinity (2 ppt) significantly raised fecundity of $P$. similis, which contributed to a high intrinsic rate of population increase. This salinity corresponds to the salinity at the sampling location of $P$. similis in nature. Population density of $P$. similis cultured at 2 ppt in batch culture was not significantly different from that at 15 ppt (Fig. 2-II), suggesting that the salinity range from 2 to 15 ppt is optimal for $P$. similis growth. Decreasing population density of $P$. similis at higher salinity may be due to the increasing energy demands for osmoregulation (Miracle and Serra, 1989) and decreased filtration rate (Hirayama and Ogawa, 1972) as reported in Brachionus. Our study also demonstrated that $P$. similis is capable of growing at a wide salinity range, indicating that $P$. similis is a euryhaline rotifer. Brain and Koste (1993) and Moscatello and Belmonte (2004) reported that the rotifer is found inhabiting hypersaline water of 48-98 ppt. Capability of $P$. similis to tolerate a wide range of salinity is probably similar to the euryhaline rotifer B. plicatilis sp. complex, which can tolerate salinity from 1 to 60 ppt as reported in Hoff and Snell (1987).

Temperature also showed strong influence on the population growth of P. similis. It has been shown that increasing temperature accelerates rotifer reproduction (Miracle and 
Serra, 1989), as a result of accelerating metabolism and development (Hirayama and Rumengan, 1993). High population growth of $P$. similis at high temperature indicates the possibility of the species to be used as first food for culturing tropical fish larvae.

$N$. oculata and C. vulgaris are the most widely used microalgal species for feeding rotifers in hatcheries and laboratories (Hoff and Snell, 1987). We successfully used these microalgae to culture $P$. similis. It has been reported that some species of rotifers including Platyias quadricornis (Enriquez-Garcia et al., 2003), Synchaeta cecilia (Egloff, 1988) and Synchaeta cecilia valentina (Oltra et al., 2000) are difficult to grow using $N$. oculata or C. vulgaris. Our result further shows that the effect of the two microalgae densities on population growth of $P$. similis was stronger at salinity 2 ppt than at $25 \mathrm{ppt}$. It is suggested that lower filtration rate at higher salinity (Hirayama et al., 1972) and low initial density of the rotifer $(1 \mathrm{ind} . / \mathrm{ml})$ in this study are probably the explanation why $P$. similis cultured at 25 ppt need lower food density for population growth. P. similis cultured at 25 ppt reached higher population density than B. rotundiformis cultured at the same food density for 8 days, indicating faster population growth rates for $P$. similis. Results in mass culture confirmed the high population growth rate of $P$. similis. From an initial density of $25 \mathrm{ind} . / \mathrm{ml}, P$. similis could reach population density of 2,400 ind./ml ( $r=$ 0.42 day $^{-1}$ ) on day 11 . Further, results of our study shows that there was no significant effect on the total number of $P$. similis,72 hours after they were transferred from 25 to 35 ppt salinity. 
P. similis is among the smallest euryhaline rotifers that have been successfully mass cultured in the laboratory (Chigbu and Suchar, 2006). Its mean body length and width were $83 \pm 11 \mu \mathrm{m}$ and $40 \pm 6 \mu \mathrm{m}$ respectively, which is $38.1 \%$ smaller and $60.3 \%$ narrower than lorica size of $B$. rotundiformis. It has been suggested that the availability of small live food organisms is important for successful rearing of fish larvae with small mouths (Eda, et al., 1990; Polo et al., 1992; Doi et al., 1997; Okumura, 1997; Tanaka et al., 2005; Olivotto et al., 2006; Akazawa et al., 2008; Soyano et al., 2008). Small live food organisms that have been offered to fish larvae include ciliate, bivalve larvae, sea urchin eggs, barnacle nauplii, oyster trochopores or copepods, but the results are still unsatisfactory due to the low nutritional value or difficulties of culturing the organisms at high density (Rimmer, 2000). As rotifers can be cultured at high density and their nutritional content can be manipulated to match fish larvae requirements, efforts to reduce the lorica size of rotifer B. plicatilis have also been conducted (Gallardo et al., 1997; Hagiwara et al., 2007). However, since lorica size is genetically constrained (Snell and Carrillo, 1984; Fu et al., 1991a,b), collecting rotifer strains with small body size from nature is also important strategy (Ito et al., 1981; Yufera, 1982; Fukusho and Okauchi, 1983; Serra and Miracle, 1983). Recently, Chigbu and Suchar (2006) reported their success in culturing Colurella dicentra, a small rotifer with lorica length of $93 \mu \mathrm{m}$ and width of $49 \mu \mathrm{m}$. But the effectiveness of this species as first food for fish larvae has not yet been examined. In this study, we demonstrated that seven-band grouper larvae feed 
actively on $P$. similis at the onset of first feeding. Grouper larvae fed $P$. similis at 20 ind./ml had a 95\% feeding incidence, while it was only 55\% for the larvae fed $B$. rotundiformis. This suggests that there is an opportunity to improve the initial survival of groupers and other small mouth fish larvae by providing $P$. similis.

The results in this study demonstrated that $P$. similis possesses characteristics that are useful for aquaculture. First, among rotifer species already used in most hatcheries, $P$. similis has the smallest body size. This species also lacks a lorica, which may result in better ingestion and digestion. Second, $P$. similis can be mass cultured using the same techniques as $B$. plicatilis, by feeding $N$. oculata or $C$. vulgaris. Third, $P$. similis is a promising live food for fish larviculture, particularly for species that require an initial food smaller than B. rotundiformis. Future study should include evaluation of culture stability and investigation of the nutritional content of $P$. similis, as well as its use for rearing trials of fish larvae to examine survival and growth.

\section{Acknowledgements}

The rotifer Proales similis was collected during the 189th cruise of Kakuyo-maru, Faculty of Fisheries, Nagasaki University in July, 2004. The authors express thanks to Terry Snell for reviewing the manuscript and Russ Shiel for identification of rotifer species.

This research was supported in part by the Ministry of Education, Science, Sports and Culture, Grant-in-Aid for Scientific Research (B), 2006-2008, No. 18380118, and the 
Nagasaki prefecture Collaboration of Regional Entities for the Advancement of Technological Excellence, Japan Science and Technology.

\section{References}

Akazawa, A., Sakakura, Y., Hagiwara, A., 2008. Feeding selectivity of marine fish larvae, Verasper variegatus, Seriola quinqueradiata and Platycephalus sp. on different sizes and shape of three rotifer strains. Nippon Suisan Gakkaishi 74, 380-388.

Brain, C.K., Koste, W., 1993. Rotifer of the genus Proales from saline springs in the Namib dessert, with the description of a new species. Hydrobiologia 255/256, 449-454.

Chigbu, P., Suchar, V.A., 2006. Isolation and culture of the marine rotifer, Collurella dicentra (Gosse, 1887) from a Mississippi Gulf Coast estuary. Aquacult. Res. 37, 1400-1405.

Doi, M., Toledo, J.D., Golez, M.S.N., Santos, M.D.L., Ohno, A., 1997. Preliminary investigation of feeding performance of larvae of early red-spotted grouper, Epinephelus coioides, reared with mixed zooplankton. Hydrobiologia 358, 259-263.

Eda, H., Murashige, R., Oozeki, Y., Hagiwara, A., Eastham, B., Bass, P., Tamaru, C.S., Lee, C.S., 1990. Factors affecting intensive larval rearing of striped mullet, Mugil cephalus. Aquaculture 91, 281-294.

Egloff, D.A., 1988. Food and growth relations of the marine microzooplankter, Synchaeta 
cecilia (Rotifera). Hydrobiologia 157, 129-141.

Enriquez-Garcia, C., Nandini, S., Sarma S.S.S., 2003. Food type effects on the population growth patterns of littoral rotifers and cladocerans. Acta Hydrochim. Hydrobiol. 31, $120-133$.

Fu, Y., Hirayama, K., Natsukari, Y., 1991a. Morphological differences between two types of the rotifer Brachionus plicatilis, O.F. Muller. J. Exp. Mar. Biol. Ecol. 151, 29-41.

Fu, Y., Hirayama, K., Natsukari, Y., 1991b. Genetic divergence between S and L type strains of the rotifer Brachionus plicatilis, O.F. Muller. J. Exp. Mar. Biol. Ecol. 151, 43-56.

Fukusho, K., Okauchi, M., 1983. Sympatry in natural distribution of the two strains of a rotifer, Brachionus plicatilis. Bull. Natl. Res. Inst. Aquacult. 4, 135-138.

Gallardo, W.G., Hagiwara, A., Tomita, A., Soyano, K., Snell, T.W., 1997. Effect of some vertebrate and invertebrate hormones on the population growth, mictic female production, and body size of the marine rotifer Brachionus plicatilis Muller. Hydrobiologia 358, 113-120.

Hagiwara, A., Kotani, T., Snell, T.W., Assava-Aree, M., Hirayama, K., 1995. Morphology, reproduction, genetics, and mating behavior of small, tropical marine Brachionus stains (Rotifera). J. Exp. Mar. Biol. Ecol. 194, 25-37.

Hagiwara, A., Gallardo, W.G., Assavaaree, M., Kotani, T., de Araujo, A.B., 2001. Live food production in Japan; recent progress and future aspects. Aquaculture 200, 
$111-127$.

Hagiwara, A., Suga, K., Akazawa, A., Kotani, T., Sakakura, Y., 2007. Development of rotifer strains with useful traits for rearing fish larvae. Aquaculture 268, 44-52.

Hirayama, K., Ogawa, S., 1972. Fundamental studies on physiology of rotifer for its mass culture. I. Filter feeding of rotifer. Bull. Jpn. Soc. Sci. Fish. 38, 1207-1214.

Hirayama, K., Rumengan, I.F.M., 1993. The fecundity patterns of S and L type rotifers of Brachionus plicatilis. Hydrobiologia 255/256, 153-157.

Hoff, F.H., Snell, T.W., 1987. Plankton culture manual, $4^{\text {th }}$ Ed. Florida Aqua Farms, Inc. Florida, USA.

Ito, S., Sakamoto, H., Hori, M., Hirayama, K., 1981. Morphological characteristics and suitable temperature for the growth of several strains of the rotifer, Brachionus plicatilis. Bull. Fac. Fish. Nagasaki Univ. 51, 9-16.

Krebs, C.J., 1985. Ecology: the experimental analysis of distribution and abundance, $3^{\text {rd }} \mathrm{Ed}$. Harper and Row, NewYork.

Lotka, A. J., 1913. A natural population norm. J. Wash. Acad. Sci. 3, 241-248, 289-293.

Miracle, M.R., Serra, M., 1989. Salinity and temperature influence in rotifer life history characteristics. Hydrobiologia 186/187, 81-102.

Moscatello, S., Belmonte, G., 2004. Active and resting stages of zooplankton and its seasonal evolution in a hypersaline temporary pond of the Mediterranean coast (the "Vecchia Salina", SE Italy). Sci. Mar. 68, 491-500. 
Okumura, S., 1997. Seed production of groupers in Japan. In: Takashima, F., Takeuchi, T., Arimoto, T., Itosu, T., (Eds), Aquaculture in Asia, Tokyo Univ. Fisheries, Tokyo, Japan. pp. 97-102.

Olivotto, I., Holt, S.A., Carnevali, O., Holt, G.J., 2006. Spawning, early development, and first feeding in the lemonpeel angelfish Centropyge flavissimus. Aquaculture 253, 270-278.

Oltra, R., Todoli, R., Bosque, T., Lubian, L.M., Navarro, J.C., 2000. Life history and fatty acid composition of the marine rotifer Synchaeta cecilia valentina fed different algae. Mar. Ecol. Prog. Ser. 193, 125-133.

Polo, A., Yufera, M., Pascual, E., 1992. Feeding and growth of gilthead seabream (Sparus aurata L.) larvae in relation to the size of the rotifer strain used as food. Aquaculture 103, 45-54.

Rimmer, M., 2000. Review of grouper hatchery technology. SPC Live Reef Fish Inform. Bull. 6, 14-15.

Rumengan, I.F.M., Warouw, V., Hagiwara, A., 1998. Morphometry and resting egg production potential of the tropical ultra-minute rotifer Brachionus rotundiformis (Manado strain) fed different algae. Bull. Fac. Fish. Nagasaki Univ. 79, 31-36.

Segers, H., 1995. Nomenclature consequences of some recent studies on Brachionus plicatilis (Rotifera, Brachionidae). Hydrobiologia 313/314, 121-122.

Serra, M., Miracle, M.R., 1983. Biometric analysis of Brachionus plicatilis ecotypes from 
Spanish lagoons. Hydrobiologia 104, 279-291.

Slamet, B., Hutapea, J.H., 2004. First successful hatchery production of Napoleon wrasse at Gondol Research Institute for Mariculture, Bali. Aquaculture Asia 9, 37.

Snell, T.W., Carrillo, K., 1984. Body size variation among strains of the rotifer Brachionus plicatilis. Aquaculture 37, 359-367.

Soyano, K., Sakakura, Y., Hagiwara, A., 2008. Reproduction and larviculture of seven-band grouper, Epinephelus septemfasciatus, in Japan. In: Liao, I.C., Leano, E.M. (Eds), The aquaculture of grouper. Asian Fisheries Society, Manila, Philippines, World Aquaculture Society, Louisiana, USA, The Fisheries Society of Taiwan, Keelung, Taiwan, and National Taiwan Ocean University, Keelung, Taiwan. pp. $1-27$.

Tanaka, Y., Sakakura, Y., Chuda, Y., Hagiwara, A., Yasumoto, S., 2005. Food selectivity of seven-band grouper Epinephelus septemfasciatus larvae fed different sizes of rotifers. Nippon Suisan Gakkaishi 71, 911-916.

Yamaoka, K., Nanbu, T., Miyagawa, M., Isshiki, T., Kusaka, A., 2000. Water surface tension-related deaths in prelarval red-spotted grouper. Aquaculture 189, 165-176.

Yufera, M., 1982. Morphometric characterization of a small-sized strain of Brachionus plicatilis in culture. Aquaculture 27, 55-61. 


\section{Figure legends}

Fig. 1. Body dimensions of Proales similis and Brachionus rotundiformis. Bar $50 \mu \mathrm{m}$.

Fig. 2. Maximum population density (mean \pm SD) of $P$. similis cultured at five temperatures at $15,20,25,30$ and $35^{\circ} \mathrm{C}$ (at $2 \square$ and 25 ppt $\square$ ) (I), and five salinities at 2, 15, 20, 25 and 30 ppt (at $25^{\circ} \mathrm{C}$ ) (II). Capital letter indicates significant difference in temperature treatment among $P$. similis at $2 \mathrm{ppt}$, while lowercase indicates significant differences among temperature treatment at $25 \mathrm{ppt}$ and among salinity treatment $(\mathrm{A}>\mathrm{B}>\mathrm{C}$, $\mathrm{a}>\mathrm{b}>\mathrm{c}$, Tukey-Kramer test, $p<0.05, \mathrm{n}=3-6)$.

Fig. 3. Maximum population density (mean $\pm \mathrm{SD}$ ) of $P$. similis and $B$. rotundiformis cultured under four densities of $N$. oculata (I) and C. vulgaris (II). Culture salinity of $P$. similis was at $2(\square)$ and 25 ( $\square$ ) ppt, and that of $B$. rotundiformis at 25 ppt ( $\boldsymbol{(}$ ). Capital letter indicates significant difference in food treatment among $P$. similis at 2 ppt, while lowercase indicates significant differences among B. rotundiformis at 25 ppt (A>B, $\mathrm{a}>\mathrm{b}>\mathrm{c}$, Tukey-Kramer test, $p<0.05, \mathrm{n}=3$ ). $\quad$ There were no significant differences among $P$. similis at 25 ppt. Asterisk indicates significant difference in population density at each food density treatments between $P$. similis and $B$. rotundiformis cultured at 25 ppt (t-test, $p<$ $0.05, n=3)$ 
Fig. 4. Histogram of body or lorica length and width of $P$. similis and $B$. rotundiformis (each $\mathrm{n}=480$ ). $\quad$ Measured rotifers were taken from culture at $25^{\circ} \mathrm{C}$ and 25 ppt fed by $N$. oculata or C. vulgaris.

Fig. 5. Population density (mean $\pm \mathrm{SD}, \mathrm{n}=3$ ) of $P$. similis mass-cultured at $25^{\circ} \mathrm{C}$ and in 25 ppt diluted seawater, fed daily by $28.8 \mu \mathrm{g}$ dry weight/ml $N$. oculata.

Fig. 6. Feeding incidence at the onset of first feeding (mean $\% \pm S D$ ) of seven-band grouper larvae (10 larvae in three replicates), fed with P. similis at 10 ind./ml (10-PS), 20 ind./ml (20-PS), 30 ind./ml (30-PS), B. rotundiformis at 10 ind./ml (10-SS) and mixed rotifers at $10 \mathrm{ind} . / \mathrm{ml}$ consisted of $5 \mathrm{ind} . / \mathrm{ml}$ of $P$. similis and $5 \mathrm{ind} . / \mathrm{ml}$ of $B$. rotundiformis (10-Mix). Letters indicate significant differences in each treatment at the same age group (a $>$ b, Tukey-Kramer test, $p<0.05, \mathrm{n}=3$ ). 


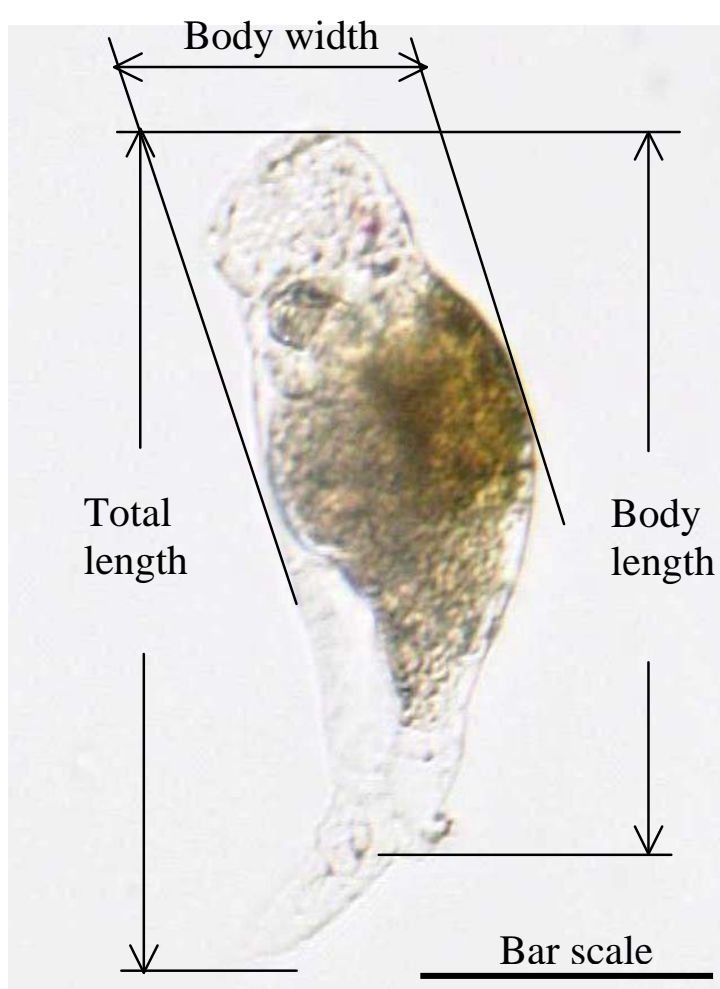

P. similis

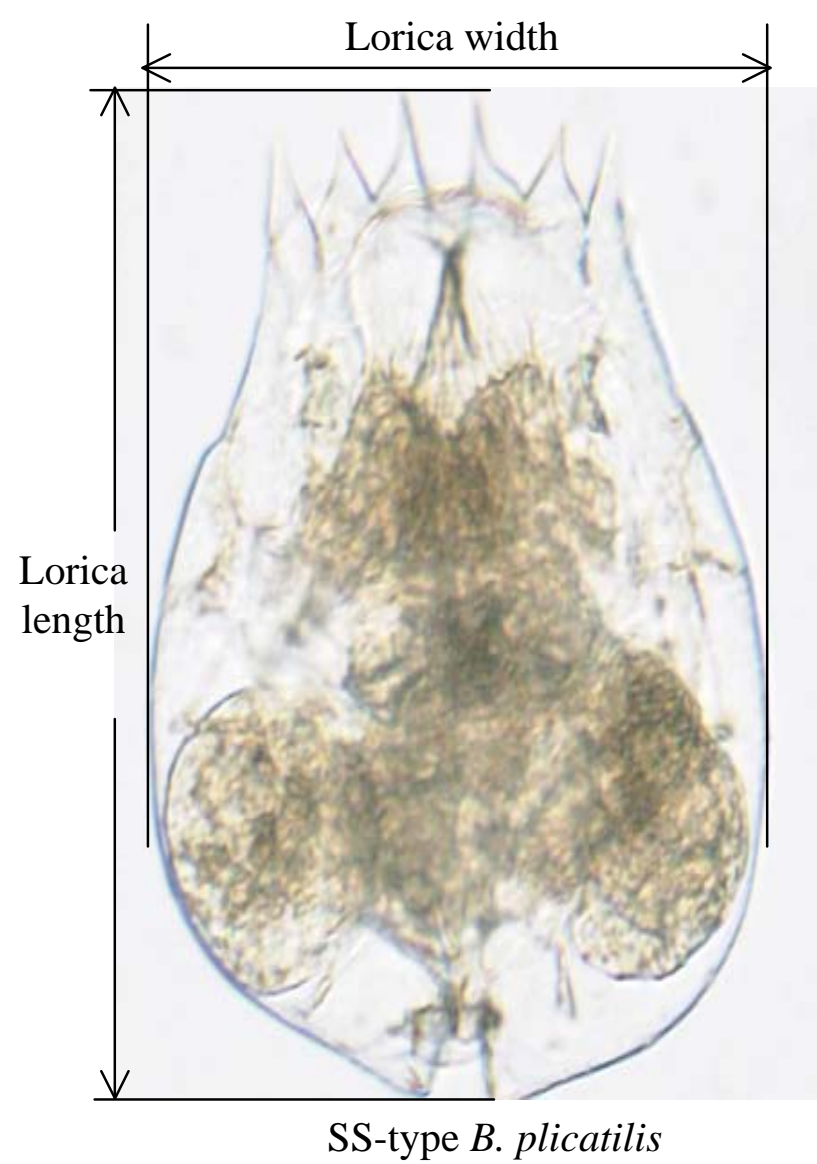

Fig. 1 

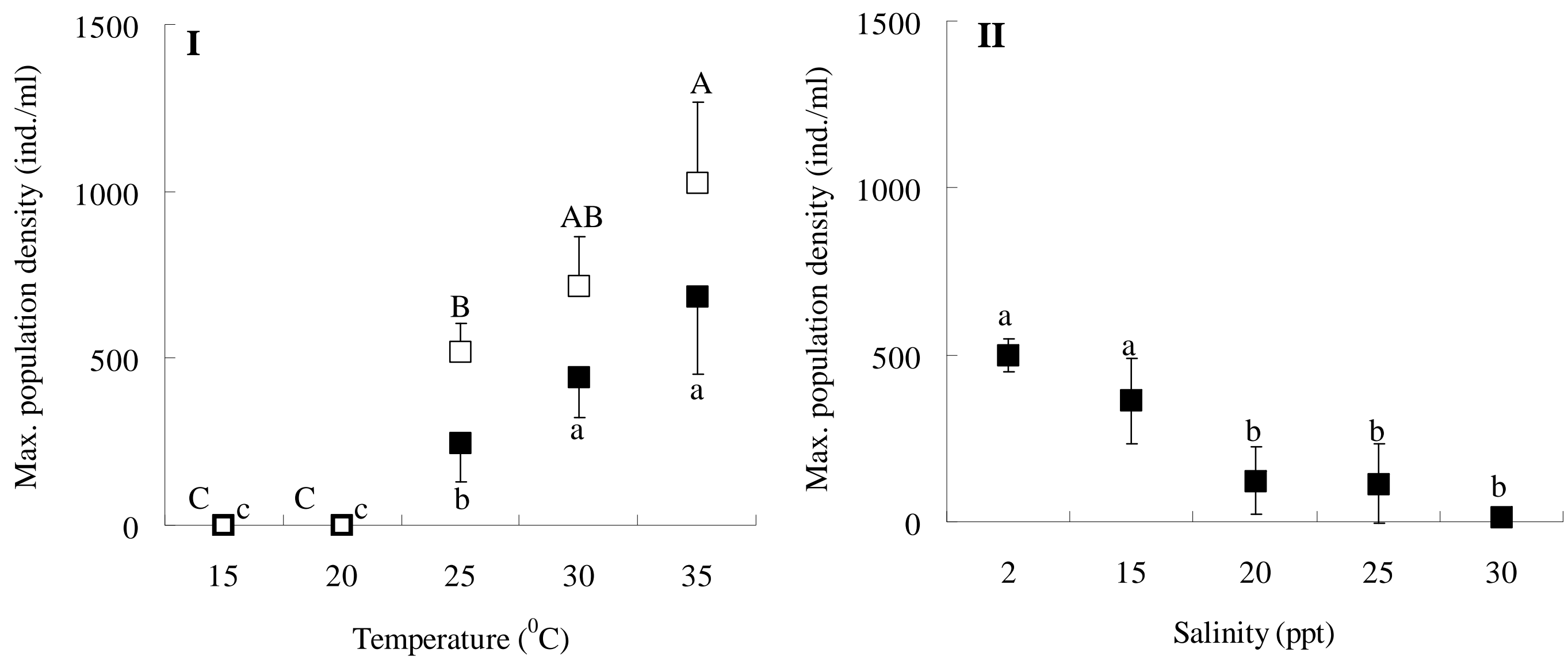

Fig. 2 

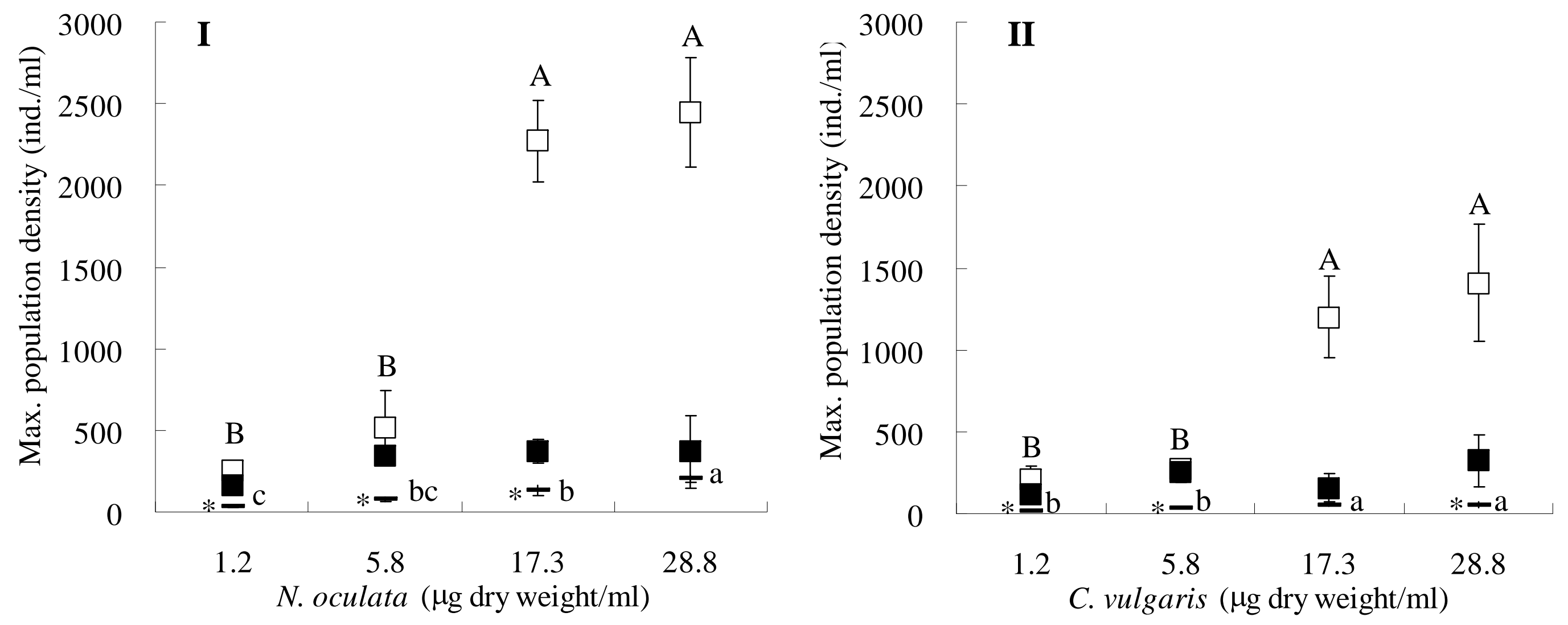

Fig. 3 

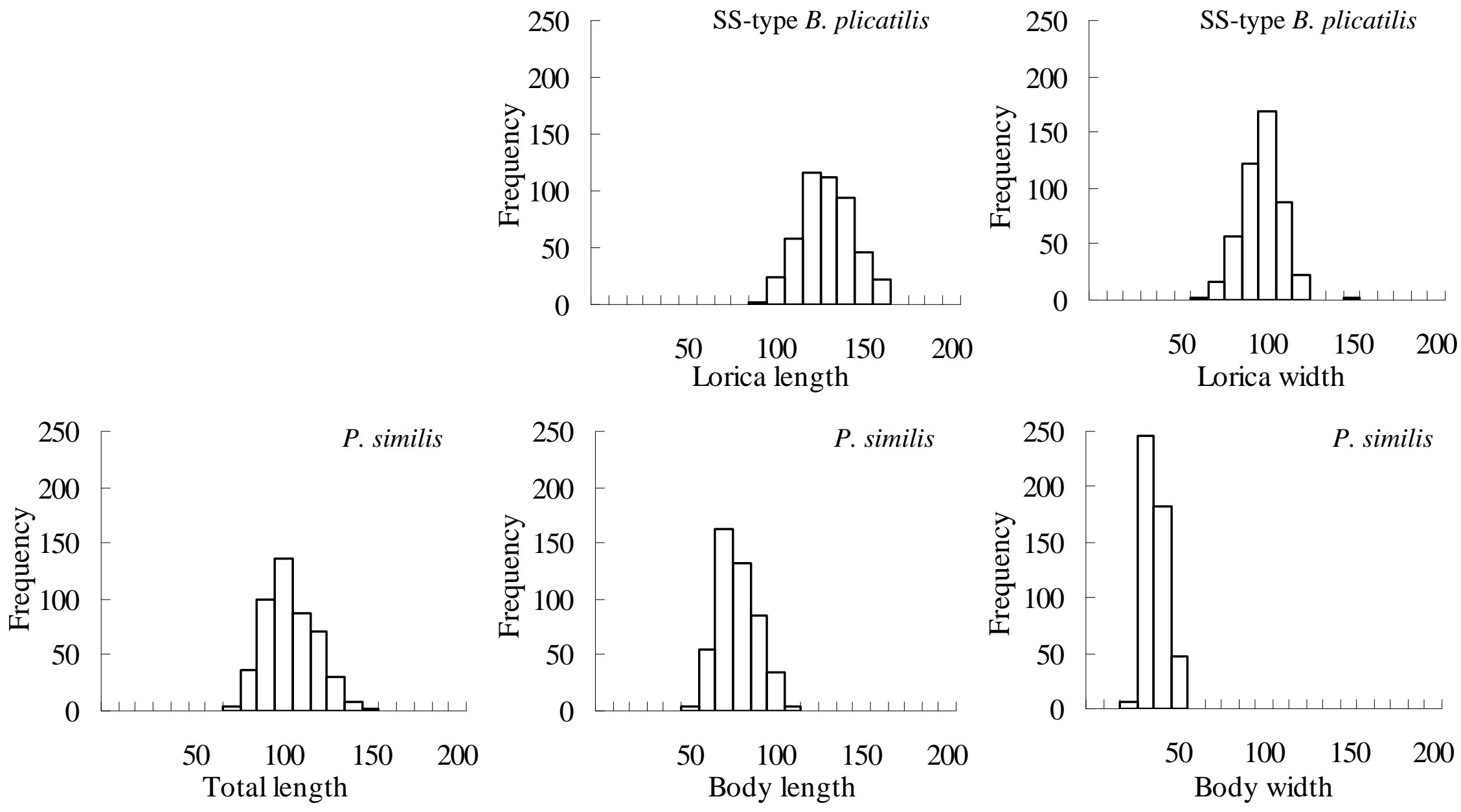

Fig. 4 


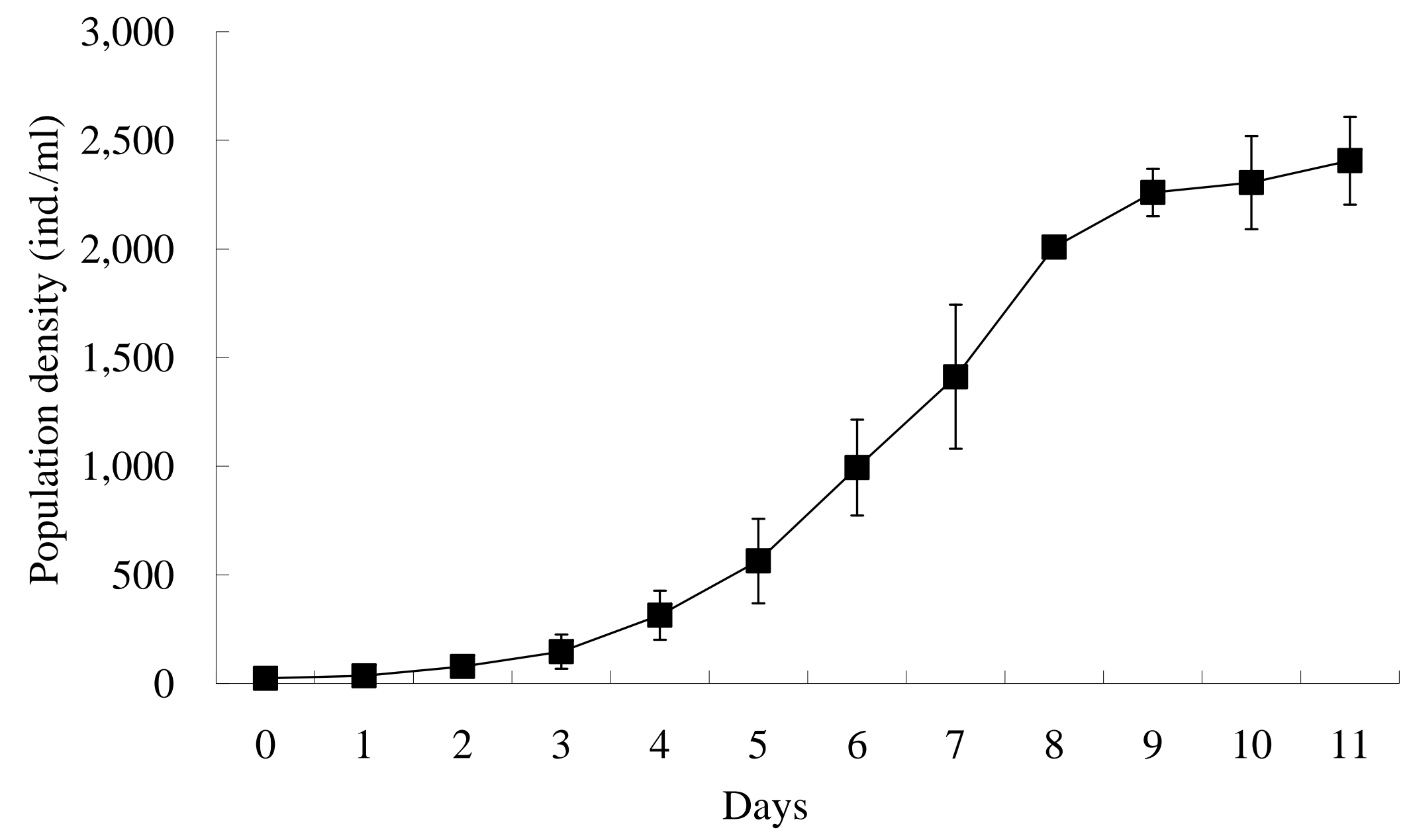

Fig. 5 


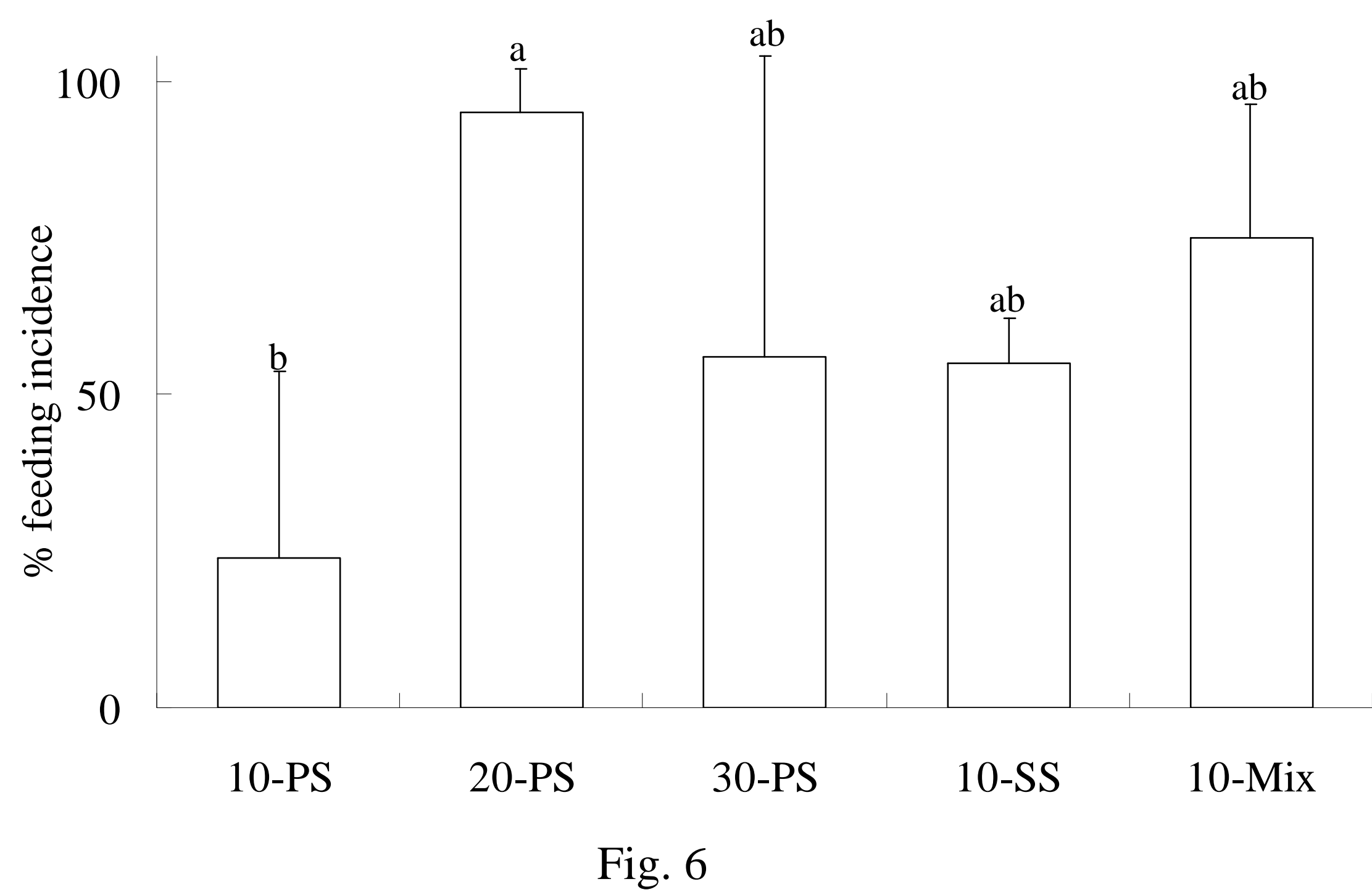


Table 1. Life history parameters of $P$. similis cultured under different levels of salinity. Data of life span, reproductive period and fecundity indicate mean \pm SD of 50 individuals.

Life history Parameters

Salinity (ppt)

\begin{tabular}{lccc}
\cline { 2 - 4 } & 2 & 15 & 25 \\
\hline Life span (days) & $4.6 \pm 1.7$ & $4.0 \pm 1.4$ & $4.7 \pm 2.0$ \\
Generation time (days) & 2.5 & 2.4 & 2.8 \\
Reproductive period (days) & $2.9 \pm 1.2$ & $3.4 \pm 1.1$ & $3.2 \pm 1.1$ \\
Fecundity (female $^{-1}$ ) & $7.8 \pm 3.9^{\mathrm{a}}$ & $4.3 \pm 1.4^{\mathrm{b}}$ & $4.3 \pm 2.6^{\mathrm{b}}$ \\
$r\left(\right.$ day $\left.^{-1}\right)$ & 0.93 & 0.70 & 0.63
\end{tabular}

a $>$ b, Tukey-Kramer post hoc test, $p<0.05$ 